\title{
Studies Regarding the Influence of Cutting Regime on Vibration and Noise Pollution in a Parts Processing
}

\author{
Mihai Demian ${ }^{1, a^{*}}$, Gabriela Demian ${ }^{1, b}$ and Stefan Radu ${ }^{1, c}$ \\ ${ }^{1}$ University of Craiova, Faculty of Mechanics, Department of Engineering and Management of \\ Technological Systems, Drobeta Turnu Severin, Romania \\ amihaidemian@yahoo.com, bgabriela demian@yahoo.com, ’stefan.radu@yahoo.com
}

Keywords: machining, cutting data, mechanical vibration, noise pollution.

\begin{abstract}
This paper presents the results of experimental research of the authors in terms of overall vibration behavior MUSD (machine tool, tool-device) during processing by removing metal on a pump body on a CNC milling and boring machine. At the research conducted in this direction were considered mechanical vibration measurements occurred during the processing of various operations of the technological process in parallel with noise measurements. These experimental research in determining the direction of vibration occurring in machining process led to some conclusions about the interdependence between the intensity and quality cutting data processing carried out and the influence of noise pollution produced.
\end{abstract}

\section{Introduction}

In recent years, highly industrialized countries methods of obtaining parts by cutting processing tools a special scale is continuously monitored cutting regime parameters and factors that lead to these changes in the process as well the noise made during processing.

The problem on dynamic aspects where machining has been investigated since the early twentieth century, Fredrick W. Taylor show that vibrations occurring in the cutting process presents a difficult aspect to control. It has demonstrated the existence of three types of vibration when cutting: free vibration, forced vibration and self-sustained vibrations as the three types of responses of mechanical systems in operation.

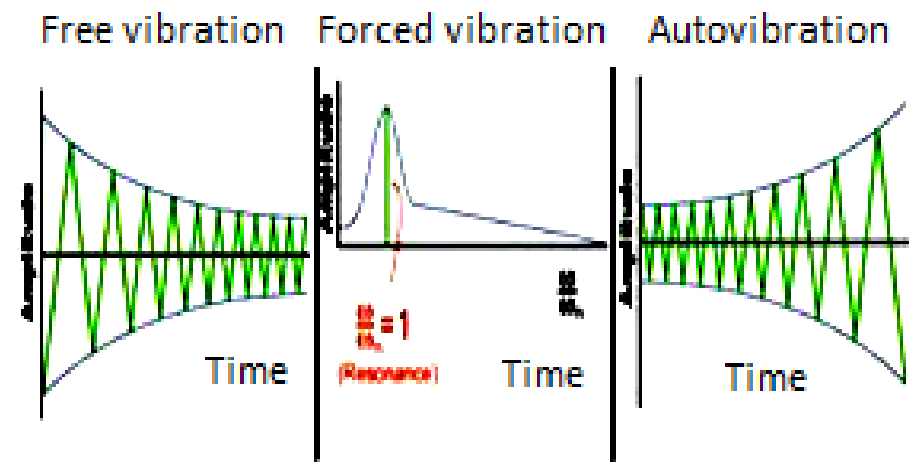

Fig.1 Types of vibrations that occur in machining [1]

\section{Materials and experimental procedure}

Cutting process is a dynamic system and vibration are determined by various components specific to the (depth of cut, feed, cutting speed, speed). In most cases, the phenomenon vibrator when machining leads to: excessive wear until the destruction of the cutting tool; poor quality surface finish, tolerances and deviations default dimensional; increased production costs implicit, requiring further treatment finishing. Therefore, vibration is almost always considered a negative factor machining because influenced in bad the surface roughness. 
There are also cases in which self-sustained vibration can be beneficial to fragmentation chip and exhaust their better processing area, such as hole diameter 2-3 $\mathrm{mm}$, and lengths of 10 to $16 \mathrm{~mm}$, as show Russian teacher V.N. Poduraev in the 50s.

Vibration frequency and amplitude were able to cause fragmentation chip, frequencies used are in the tens of $\mathrm{Hz}$ and amplitude of the vibrations reaching values of the order of millimeters. Cutting regimes thus determine a specific frequency and vibration amplitude and noise pollution depending on operating parameters.

In the calculation of vibration following formulas were used relations like:

$X=X_{\text {virf }} \sin \omega t$

if $\sin (\omega t)=1$, than $\mathrm{X}=\mathrm{X}_{\mathrm{virf}}$

$\mathrm{X}_{\mathrm{virf}}=$ are singular values are removed for a better description of the movement, in practice mean square values $X_{\text {RMS }}$ and $V_{\text {RMS }}$

$\mathrm{X}_{\mathrm{RMS}}=\sqrt{\frac{1}{\mathrm{~T}} \int_{0}^{\mathrm{T}} \mathrm{X}^{2}(\mathrm{t}) \mathrm{dt}} \quad(\mathrm{RMS}=$ root mean square $)$

where $-\mathrm{T}=$ period movement and $\mathrm{t}=$ time

for a harmonic motion integral above becomes:

$X_{R M S}=\sqrt{2} X_{\text {virf }}$

$v=\frac{d x}{d t}=\omega X_{\text {virf }} \cos (\omega t)=\omega X_{\text {virf }}$

for $\cos (\omega t)=1$

$v_{\text {virf }}=\omega X_{\text {virf }}$

$v_{R M S}=\omega \frac{X_{R M S}}{\sqrt{2}}$

$v_{R M S}=2 \pi f \frac{X_{R M S}}{2}$

$X_{R M S}=\frac{\sqrt{2} v_{R M S}}{2 \pi f},[\mathrm{~mm}]$

$\frac{n}{60}=f$

$X(\mathrm{~nm})_{R M S}=X_{R M S} 1000,[\mathrm{~nm}]$

The experiments were made on a CNC Milling and boring machines AFP 180
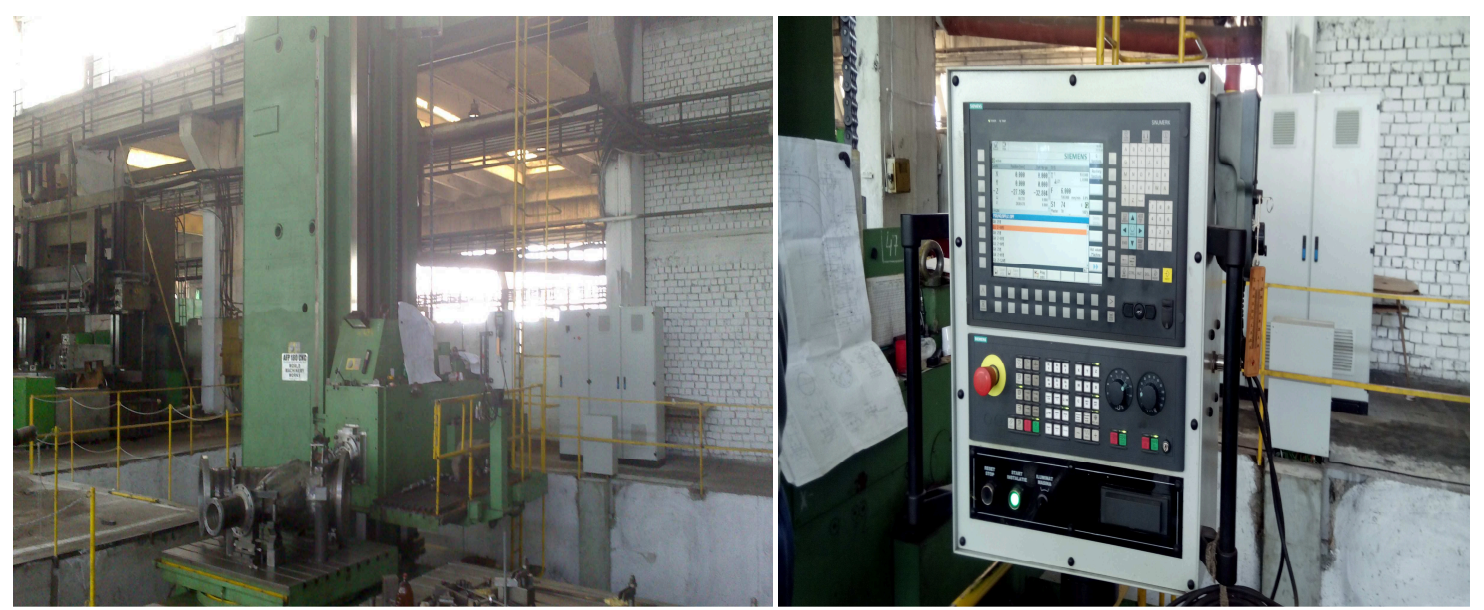

Fig.2 CNC Milling and boring machines AFP 180 
For the measurements of the noise pollution were used a Volcraft device SL 451 (fig. 3) and for the vibrations were used a vibrometer SKF Microlog CMVA 60 (fig. 4).

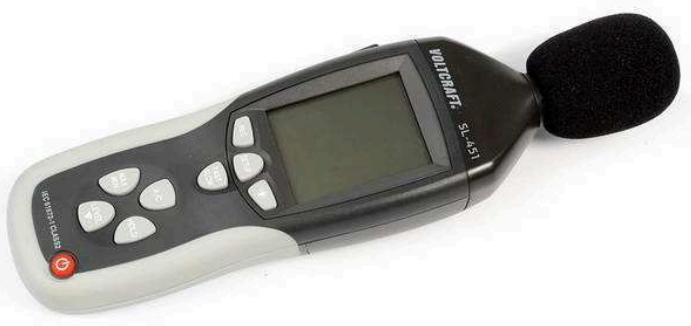

Fig.3 Volcraft SL 451

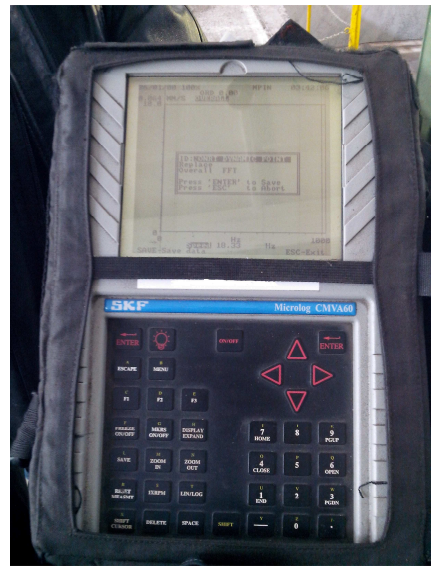

Fig.4 Vibrometer SKF Microlog CMVA 60

The devices were put in optimal position to obtain precise measurements. Measurements scheme for vibration and noise pollution are presented in fig. 5.

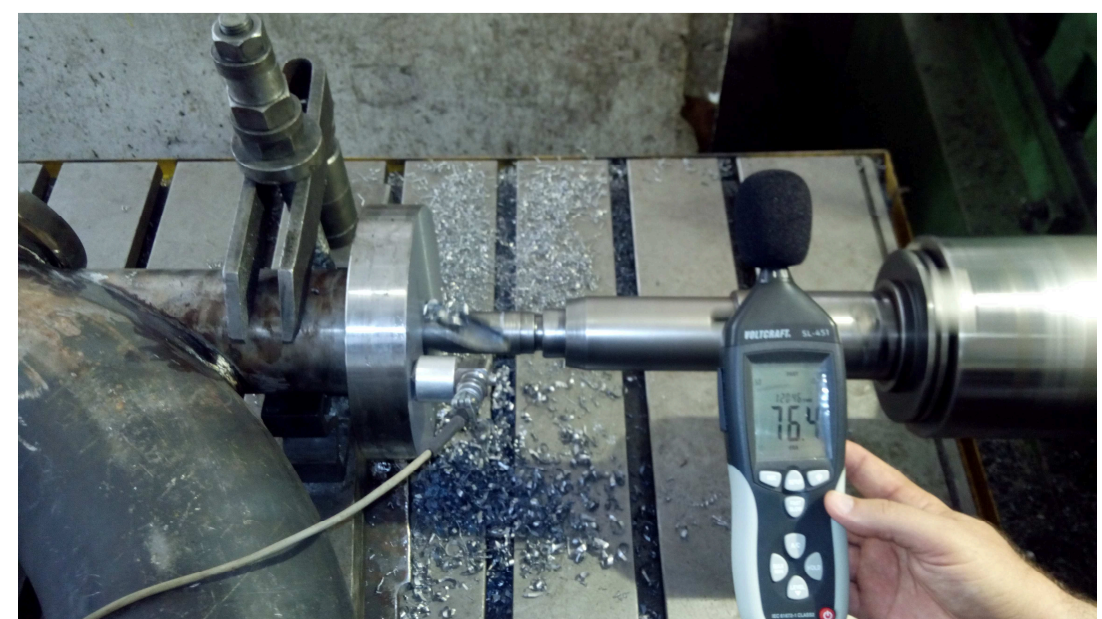

Fig.5 Measurements scheme for vibration and noise pollution

\section{Results and discussion}

In experimental research program was provided measurements of noise and vibration measurements $[2,3,4]$. Noise measurements were performed in parallel with vibration measurements (table 1 and 2). 
Table 1. Vibrations and noise measurements for the table of milling and boring machines

\begin{tabular}{|c|c|c|c|c|}
\hline & $\begin{array}{c}\text { Position } \\
\text { Accelerometer }\end{array}$ & $\begin{array}{l}\text { Speed } \\
v_{R M S}\end{array}$ & $\begin{array}{c}\text { Amplitude } \\
X_{R M S}[\mu \mathrm{m} / \mathrm{mm}]\end{array}$ & $\begin{array}{l}\text { sound intensity } \\
\mathrm{dB}\end{array}$ \\
\hline \multirow{12}{*}{ 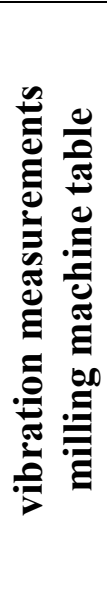 } & \multicolumn{4}{|c|}{ speed: 74 rot. / min. advance: $10 \mathrm{~mm} / \mathrm{min}}$. \\
\hline & Axial & 1,850 & 337,615 & \multirow{3}{*}{76,4} \\
\hline & Horizontal & 0,990 & 180,67 & \\
\hline & Vertical & 1,060 & 193,445 & \\
\hline & \multicolumn{4}{|c|}{ speed: 77 rot. $/$ min. advance: $8 \mathrm{~mm} / \mathrm{min}$. } \\
\hline & Axial & 1,52 & 266,58 & \multirow{3}{*}{77,6} \\
\hline & Horizontal & 1,07 & 187,66 & \\
\hline & Vertical & 1,18 & 206,95 & \\
\hline & \multicolumn{4}{|c|}{ speed: 84 rot. $/$ min. advance: $8 \mathrm{~mm} / \mathrm{min}$. } \\
\hline & Axial & 1,100 & 176,845 & \multirow{3}{*}{79,1} \\
\hline & Horizontal & 1,150 & 184,885 & \\
\hline & Vertical & 1,300 & 209,00 & \\
\hline
\end{tabular}

Table 2. Vibrations and noise measurements for the piece on the milling and boring machines

\begin{tabular}{|c|c|c|c|c|}
\hline & $\begin{array}{c}\text { Position } \\
\text { Accelerometer }\end{array}$ & $\begin{array}{l}\text { Speed } \\
v_{R M S}\end{array}$ & $\begin{array}{c}\text { Amplitude } \\
X_{R M S}[\mu \mathrm{m} / \mathrm{mm}]\end{array}$ & $\begin{array}{l}\text { sound intensity } \\
\mathrm{dB}\end{array}$ \\
\hline \multirow{12}{*}{ 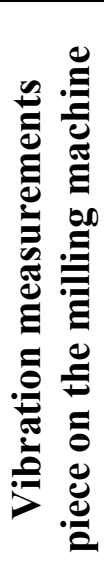 } & \multicolumn{4}{|c|}{ speed: 74 rot. $/ \mathrm{min}$. advance: $6 \mathrm{~mm} / \mathrm{min}$} \\
\hline & Axial & 0,310 & 56,575 & \multirow{3}{*}{76,4} \\
\hline & Horizontal & 0,780 & 142,345 & \\
\hline & Vertical & 0,480 & 87,595 & \\
\hline & \multicolumn{4}{|c|}{ speed: 77 rot. / min. advance: $6 \mathrm{~mm} / \mathrm{min}$. } \\
\hline & Axial & 0,605 & 106,107 & \multirow{3}{*}{77,6} \\
\hline & Horizontal & 0,745 & 139,661 & \\
\hline & Vertical & 0,521 & 91,375 & \\
\hline & \multicolumn{4}{|c|}{ speed: 84 rot. $/ \mathrm{min}$. advance: $6 \mathrm{~mm} / \mathrm{min}$. } \\
\hline & Axial & 0,900 & 144,69 & \multirow{3}{*}{79,1} \\
\hline & Horizontal & 0,720 & 115,755 & \\
\hline & Vertical & 0,560 & 90.03 & \\
\hline
\end{tabular}

Vibration measurements were performed on the three axes; axial, vertical and horizontal. Vibration measurements were conducted for milling machine table and for the part of the grip on the drill table. In the calculation of vibration were used formulas from the chapter Materials and experimental procedure.

\section{Conclusions}

The first conclusion that can be drawn from the experimental tests is that the vibrations of the mounting jig are higher than those of the milling machine table. This indicates that the work piece mounting jig is improper and he must be redesigned so that differences in measurement of vibration amplitude for milling machine table and for the piece of the grip of on the mill mass to be very small.

A second conclusion is that with the increase of the cutting regime parameters, increases the amplitude of vibration and noise pollution.

A third conclusion that can be drawn from the experimental tests is that noise pollution exceeds acceptable limits of standards and so on milling machine worker must wear protective equipment or use a cutting regime parameters diminished. 
Noise pollution and vibration is an important element in finding an optimal cutting regime together with cutting depth [mm]; advance [mm/rev]; cutting speed [m/min].

Future experimental program will try to determine the optimal balance between performance of cutting regime, reduced vibrations in the processing and smaller noise pollution values, because all of this influenced the surface roughness.

\section{References}

[1] Ivan, R.A., Dynamic aspect's study of the tool holder-milling cutter-work piece system, in high speed milling case, $\mathrm{PhD}$. thesis, Braşov (2011).

[2] Man Mahendra Singh, Study the effect of different operating parameters on noise during turning operation in a centre lathe machine, Thapar University, Patiala (2010).

[3] Pranali Khatake, Nitnaware P. T., Vibration mitigation using passive damper in machining, International Journal of Modern Engineering Research (IJMER) Vol. 3, Issue. 6, Nov - Dec. 2013 pp-3649-3652 ISSN: 2249-66454.

[4] Bogdan Bucur, Vasile Bolos, Experimental research on noise and vibration level of gearbox using worm face-gear with reverse tapered pinion, The 5th Edition of the Interdisciplinarity in Engineering international Conference "Petru Maior" University of Tirgu Mures, Romania (2011). 